\title{
PENGARUH NON PERFORMING FINANCING DAN FINANCING TO DEPOSIT RATIO TERHADAP PEMBIAYAAN PADA BANK DKI SYARIAH
}

\author{
${ }^{1 *}$ Najibullah, ${ }^{2}$ Nurjaya \\ ${ }_{1}^{1}$ STIE Hidayatullah, Depok, Jawa Barat, Indonesia \\ ${ }^{2}$ Universitas Suryakancana, Cianjur, Jawa Barat, Indonesia \\ *najibullah@stiehidayatullah.ac.id
}

\begin{abstract}
Abstrak
Penelitian ini bertujuan untuk mengetahui Pengaruh Non Performing Financing dan Financing to Deposit Ratio Terhadap Pembiayaan Pada Bank DKI Syariah. Metode yang digunakan adalah explanatory research. Teknik analisis menggunakan analisis statistik dengan pengujian regresi, korelasi, determinasi dan uji hipotesis. Hasil penelitian ini Non Performing Financing berpengaruh negatif signifikan terhadap Pembiayaan sebesar 54,9\%, uji hipotesis diperoleh t hitung $<\mathrm{t}$ tabel atau $(-2,920<2,365)$. Financing to Deposit Ratio berpengaruh negatif signifikan terhadap Pembiayaan sebesar 52,1\%, uji hipotesis diperoleh t hitung < t tabel atau $(-2,759<2,365)$. Non Performing Financing dan Financing to Deposit Ratio secara simultan berpengaruh negatif namun tidak signifikan terhadap Pembiayaan diperoleh persamaan regresi $\mathrm{Y}=39,568-0,630 \mathrm{X} 1-0,132 \mathrm{X} 2$ dan nilai determinasi sebesar 57,9\%, uji hipotesis diperoleh nilai $\mathrm{F}$ hitung $<\mathrm{F}$ tabel atau $(4,110<4,760)$.
\end{abstract}

Kata Kunci: Non Performing Financing, Financing to Deposit Ratio, Pembiayaan.

\begin{abstract}
This study aims to determine the effect of Non Performing Financing and Financing to Deposit Ratio on Financing at Bank DKI Syariah. The method used is explanatory research. The analysis technique uses statistical analysis with regression testing, correlation, determination and hypothesis testing. The results of this study Non Performing Financing has a significant negative effect on financing by 54.9\%, hypothesis testing obtained $t$ count $<t$ table or $(-2.920<2.365)$. Financing to Deposit Ratio has a significant negative effect on financing by $52.1 \%$, hypothesis testing is obtained t count $<$ t table or $(-2,759<2,365)$. Simultaneously Non Performing Financing and Financing to Deposit Ratio have a negative but insignificant effect on financing, the regression equation $Y=39.568-0.630 X 1-0.132 X 2$ and a determination value of $57.9 \%$, hypothesis testing obtained $F$ value $<F$ table or $(4,110<4,760)$.
\end{abstract}

Keywords: Non Performing Financing, Financing to Deposit Ratio, Financing.

\section{PENDAHULUAN}

Dengan semakin berkembangnya perekonomian suatu Negara, semakin tinggi pula tingkat permintaan masyarakat akan permintaan atau kebutuhan dana. Namun, dana pemerintah yang bersumber dari APBN sangat terbatas untuk memenuhi kebutuhan dana diatas, maka pemerintah mengajak dan mendorong swasta untuk turut serta berperan dalam membiayai pembangunan potensi ekonomi bangsa. Pihak swasta pun, secara individual maupun kelembagaan, kepemilikan dananya juga terbatas untuk memenuhi operasional dan pengembangan usahanya. Dengan keterbatasan kemampuan keuangan lembaga Negara dan swasta tersebut, maka perbankan nasional akan memegang peranan penting dan strategis dalam kaitannya penyediaan permodalan pengembangan sector-sektor produktif.
Bank sebagai lembaga perantara jasa keuangan (Financial intermediary), yang tugasnya adalah menghimpun dana dari masyarakat dan menyalurkan dana kepada masyarakat. Menurut Undang-Undang No. 7 tahun 1992 tentang perbankan, perbankan nasional Indonesia menganut dual banking system yaitu, sistem perbankan konvensional dan sistem perbankan syariah. Sistem perbankan konvensional seperti yang kita ketahui menggunakan bunga (interest) sebagai landasan operasionalnya. Berbeda halnya dengan perbankan konvensional yang menggunakan bunga sebagai landasan operasionalnya, sistem perbankan syariah menggunakan prinsip bagi hasil sebagai landasan dasar bagi operasionalnya secara keseluruhan.

Bank syariah adalah Bank yang menjalankan kegiatan usahanya berdasarkan 
prinsip-prinsip syariah. Prinsip syariah adalah prinsip hukum islam dalam kegiatan perbankan berdasarkan fatwa yang dikeluarkan oleh lembaga yang memiliki kewenangan dalam penetapan fatwa dibidang syariah. Bank islam atau bank syariah telah berkembang pesat selama beberapa tahun terakhir serta telah menjadi tren yang sangat penting dalam dunia keuangan. Dimana produk dan jasa keuangan yang ditawarkan harus sesuai dengan Syariah atau hukum Islam. Dalam kegiatan usahanya, bank-bank syariah, baik bank umum syariah, unit usaha syariah, dan bank pembiayaan syariah memberikan fasilitas-fasilitas pembiayaan berupa pembiayaan berdasarkan prinsip bagi hasil (mudharabah), pembiayaan berdasarkan prinsip usaha patungan (musyarakah), jual beli barang dengan memperoleh Keuntungan atau margin (murabahah, salam, istishna), atau pembiayaan barang modal berdasarkan prinsip sewa (ijarah) dan juga qardh.

Meningkatnya jumlah bank dan kantor perbankan syariah yang beroperasi di Indonesia ini memberikan dampak yang positif bagi perkembangan industry perbankan syariah. Peningkatan ini memberikan kemudahan bagi masyarakat Indonesia untuk dapat menikmati layanan dari perbankan syariah. Selain berpengaruh terhadap pertumbuhan penghimpunan Dana Pihak Ketiga (DPK), meningkatnya jumlah bank dan kantor bank syariah juga berpengaruh terhadap pertumbuhan penyaluran pembiayaan perbankan syariah.

Dalam sepuluh tahun terakhir industri perbankan syariah selalu mengalami pertumbuhan yang positif, baik dalam pengumpulan DPK maupun penyaluran pembiayaan. Efektifitas sebuah bank dalam menjalankan fungsinya sebagai lembaga intermediasi dapat dilihat dari nilai Loan to Deposit Ratio (pada bank konvensional) atau nilai Financing to Deposit Ratio (pada bank syariah) bank tersebut. Semakin besar nilai Loan to Deposit Ratio / Financing to Deposit Ratio sebuah bank maka semakin efektif pula bank tersebut dalam menjalankan fungsinya sebagai lembaga intermediasi.

Nilai FDR pada bank syariah mengalami kenaikan yang cukup signifikan dari tahun ketahun hingga mencapai $100 \%$, meskipun pada beberapa tahun terakhir nilainya mengalami penurunan namun tetap lebih tinggi dibanding tahun 2010-2011. Hal ini berarti selain seluruh DPK yang berhasil dikumpulkan oleh perbankan syariah disalurkan kembali sebagai pembiayaan, modal yang dimiliki perbankan syariah pun juga ikut disalurkan.

Tetapi jika dilihat dari sisi lain FDR yang tinggi dapat juga dikatakan bahwa perbankan syariah mengalami likuiditas yang sangat ketat. Likuiditas yang sangat ketat akan menimbulkan risiko likuiditas yang tinggi. Risiko likuiditas yang tinggi ini sangat berbahaya jika perbankan syariah tidak bisa mengelolanya dengan baik.

Sebab, pemicu utama kebangkrutan sebuah bank, baik besar atau kecil, bukanlah karena kerugian yang dideritanya, melainkan lebih kepada ketidakmampuan bank tersebut memenuhi kebutuhan likuiditasnya. Likuiditas yang tersedia harus cukup, tidak boleh terlalu kecil dan juga tidak boleh terlalu besar. Likuiditas yang kecil dapat mengganggu kebutuhan operasional seharihari sebuah bank sedangkan likuiditas yang besar akan menurunkan efisiensi dan pada akhirnya akan berdampak pada rendahnya tingkat profitabilitas. Selain itu, hal lainnya yang perlu diperhatikan oleh bank syariah adalah mengenai Non Performing Financing (NPF) dimana nilainya juga fluktuatif dengan kecenderungan menurun meskipun nilai tersebut masih dalam Ambang batas aman yang ditetapkan Bank Indonesia.

Berdasarkan apa yang telah penulis uraikan diatas maka penulis memutuskan untuk melakukan penelitian dengan konsentrasi syariah tentang NPF dan FDR dan pengaruhnya terhadap pembiayaan pada bank syariah. Adapun judul yang diajukan oleh penulis yaitu "Pengaruh Non Performing Financing dan Financing to Deposit Ratio Terhadap Pembiayaan Bank DKI Syariah"

\section{TINJAUAN PUSTAKA}

\section{Non Performing Financing}

NPF (Nonperforming financing) adalah rasio antara pembiayaan yang bermasalah dengan total pembiayaan yang disalurkan oleh bank syariah. Dalam praktik perbankan sehari-hari, menurut Dendawijaya (2005:82) dalam Jurnal Ekonomi Mutamimah Pembiayaan bermasalah adalah pembiayaan- 
pembiayaan yang kategori kolektabilitasnya masuk dalam kriteria pembiayaan kurang lancar, pembiayaan diragukan, dan pembiayaan macet.

\section{Financing to Deposit Ratio}

Pengertian FDR (Financing to Deposit Ratio) menurut veitzhal rivai (2010:785) adalah perbandingan antara pembiayaan yang diberikan oleh bank dengan dana pihak ketiga yang berhasil dikerahkan oleh bank. Rasio ini dipergunakan untuk mengukur sampai sejauh mana dana pinjaman yang bersumber dari dana pihak ketiga. Tinggi rendahnya rasio ini menunjukkan tingkat likuiditas bank tersebut. Sehingga semakin tinggi angka FDR suatu bank, berarti digambarkan sebagai bank yang kurang likuid dibanding dengan bank yang mempunyai angka rasio lebih kecil.

\section{Pembiayaan}

Pengertian pembiayaan menurut Veithzal Rivai (2010: 681) adalah pendanaan yang diberikan oleh suatu pihak kepada pihak lain untuk mendukung investasi yang telah direncanakan, baik dilakukan sendiri maupun lembaga. Dengan kata lain pembiayaan adalah pedanaan yang dikeluarkan untuk mendukung investasi yang telah direncanakan.

\section{METODE}

Populasi dalam penelitian ini berdasar laporan keuangan selama 9 tahun Bank DKI Syariah. Teknik pengambilan sampling dalam penelitian ini adalah samplel jenuh, dimana semua anggota populasi dijadikan sebagai sampel. Dengan demikian sampel dalam penelitian ini laporan keuangan selama 9 tahun. Jenis penelitian yang dipakai adalah asosiatif, dimana tujuannya adalah untuk mengetahui mencari keterhubungan antar variabel independen terhadap variabel dependen. Dalam menganalisis data digunakan uji asumsi klasik, regresi, koefisien korelasi, koefisien determinasi dan uji hipotesis baik parsial maupun simultan.

\section{HASIL DAN PEMBAHASAN}

\section{Analisis Deskriptif}

Pada pengujian ini digunakan untuk mengetahui besarnya persentase minimum dan maksimum, persentase rata-rata dan standar deviasi dari masing-masing variabel. Adapun hasilnya sebagai berikut:

Tabel 1. Hasil Analisis Descriptive Statistics

Descriptive Statistics

$\mathrm{N}$ Minimum Maximum Mean Std. Deviation

\begin{tabular}{|l|r|r|r|r|r|}
\hline NPL (X1) & 9 & 9.6 & 21.3 & 17.323 & 3.5894 \\
\hline FDR (X2) & 9 & 65.2 & 101.2 & 85.926 & 12.1507 \\
\hline Pembiayaan (Y) & 9 & 10.8 & 22.8 & 17.294 & 4.9045 \\
\hline Valid N (listwise) & 9 & & & & \\
\hline
\end{tabular}

Non Performing Financing diperoleh nilai minimum sebesar 9,6 dan nilai maximum 21,3 dengan rata-rata sebesar 17,32 dengan standar deviasi 3,589 .

Financing to Deposit Ratio diperoleh nilai minimum sebesar 65,2 dan nilai maximum 101,2 dengan nilai rata-rata sebesar 85,92 dengan standar deviasi 12,150

Pembiayaan diperoleh nilai minimum sebesar 10,8 dan nilai maximum 22,8 dengan rata-rata sebesar 17,29 dengan standar deviasi 4,904.

\section{Analisis Verifikatif}

Pada analisis ini dimaksudkan untuk mengetahui pengaruh variabel independen terhadap variabel dependen. Adapun hasil pengujian sebagai berikut:

\section{a. Analisis Regresi Linier Berganda}

Uji regresi ini dimaksudkan untuk mengetahui perubahan variabel dependen jika variabel independen mengalami perubahan. Adapun hasil pengujiannya sebagai berikut: 
Tabel 2. Hasil Pengujian Regresi Liner Berganda Coefficients ${ }^{a}$

Unstandardized Coefficients Standardized Coefficients

\begin{tabular}{|c|c|c|c|c|c|}
\hline Model & $\mathrm{B}$ & Std. Error & Beta & $t$ & Sig. \\
\hline 1 (Constant) & 39.568 & 9.771 & & 4.050 & .007 \\
\hline$N P L(X 1)$ & -.630 & .699 & -.461 & -.901 & .402 \\
\hline$F D R(X 2)$ & -.132 & .206 & -.328 & -.641 & .545 \\
\hline
\end{tabular}

a. Dependent Variable: Pembiayaan (Y)

Berdasarkan hasil pengujian pada tabel di atas, diperoleh persamaan regresi $Y=39,568-0,630 X 1-0,132 X 2$. Dari persamaan tersebut dijelaskan sebagai berikut:

1) Konstanta sebesar 39,568 diartikan jika Non Performing Financing dan Financing to Deposit Ratio tidak ada, maka telah terdapat nilai Pembiayaan sebesar 39,568 point.

2) Koefisien regresi Non Performing Financing sebesar $-0,630$, angka ini negatif artinya setiap ada peningkatan Non Performing Financing sebesar $-0,630$ maka Pembiayaan akan mengalami penurunan sebesar $-0,630$ point.

Tabel 3. Hasil Pengujian Koefisien Korelasi Non Performing Financing Terhadap Pembiayaan

Correlations $^{\mathrm{b}}$

\begin{tabular}{llr|r} 
& & NPL (X1) & Pembiayaan (Y) \\
\hline NPL (X1) & Pearson Correlation & 1 & $-.741^{*}$ \\
\cline { 2 - 4 } & Sig. (2-tailed) & & .022 \\
\hline Pembiayaan (Y) & Pearson Correlation & $-.741^{*}$ & 1 \\
\cline { 2 - 4 } & Sig. (2-tailed) & .022 & \\
\hline
\end{tabular}

Berdasarkan hasil pengujian diperoleh nilai korelasi sebesar $-0,741$ artinya Non Performing Financing

Tabel 4. Hasil Pengujian Koefisien Korelasi Financing to Deposit Ratio Terhadap Pembiayaan

Correlations $^{\mathrm{b}}$

\begin{tabular}{llr|r} 
& & FDR (X2) & Pembiayaan (Y) \\
\hline FDR (X2) & Pearson Correlation & 1 & $-.722^{*}$ \\
\cline { 2 - 4 } & Sig. (2-tailed) & & .028 \\
\hline Pembiayaan (Y) & Pearson Correlation & $-.722^{*}$ & 1 \\
\cline { 2 - 4 } & Sig. (2-tailed) & .028 & \\
\hline
\end{tabular}

Berdasarkan hasil pengujian diperoleh nilai korelasi sebesar $-0,722$ artinya Financing to Deposit Ratio memiliki hubungan yang negatif kuat terhadap Pembiayaan.

Tabel 5. Hasil Pengujian Koefisien Korelasi Non Performing Financing dan Financing to Deposit Ratio secara simultan Terhadap Pembiayaan

Model Summary

\begin{tabular}{lc|r|r|r} 
Model & R & R Square & Adjusted R Square & Std. Error of the Estimate \\
\hline 1 & $.760^{\mathrm{a}}$ & .578 & .437 & 3.6787
\end{tabular}


a. Predictors: (Constant), FDR (X2), NPL (X1)

Berdasarkan hasil pengujian diperoleh nilai korelasi sebesar 0,760 artinya Non Performing Financing dan Financing to Deposit Ratio secara simultan memiliki hubungan yang kuat terhadap Pembiayaan

\section{c. Analisis Koefisien Determinasi}

Analisis koefisien determinasi dimaksudkan untuk mengetahui besarnya persentase pengaruh dari variabel independen terhadap variabel dependen baik secara parsial maupun simultan. Adapun hasil pengujian sebagai berikut:

Tabel 6. Hasil Pengujian Koefisien Determinasi Non Performing Financing Terhadap

Pembiayaan

Model Summary

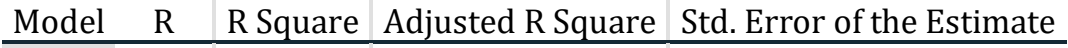

\begin{tabular}{lllll}
\hline 1 & $.741^{\mathrm{a}}$ & .549 & .485 & 3.5205 \\
\hline
\end{tabular}

a. Predictors: (Constant), NPL (X1)

Berdasarkan hasil pengujian diperoleh nilai determinasi sebesar 0,549 artinya Non Performing

Financing memiliki kontribusi pengaruh sebesar $54,9 \%$ terhadap Pembiayaan.

Tabel 7. Hasil Pengujian Koefisien Determinasi Financing to Deposit Ratio Terhadap

Pembiayaan

Model Summary

\begin{tabular}{ll|l|l|l|} 
Model & $\mathrm{R}$ & R Square & Adjusted R Square & Std. Error of the Estimate \\
\hline 1 & &
\end{tabular}

\begin{tabular}{lrrrr}
\hline 1 & $.722^{\mathrm{a}}$ & .521 & .452 & 3.6290 \\
\hline a. Predictors: (Constant), FDR $(X 2)$ &
\end{tabular}

Berdasarkan hasil pengujian diperoleh nilai determinasi sebesar

0,521 artinya Financing to Deposit Ratio memiliki kontribusi pengaruh sebesar 52,1\% terhadap Pembiayaan.

Tabel 8. Hasil Pengujian Koefisien Determinasi Non Performing Financing dan Financing to Deposit Ratio Terhadap Pembiayaan

Model Summary

\begin{tabular}{ll|l|l|l} 
Model & R & R Square & Adjusted R Square & Std. Error of the Estimate \\
\hline 1 & &
\end{tabular}

\begin{tabular}{rrrrr}
\hline 1 & $.760^{\mathrm{a}}$ & .578 & .437 & 3.6787 \\
\hline
\end{tabular}

a. Predictors: (Constant), FDR (X2), NPL (X1)

Berdasarkan hasil pengujian diperoleh nilai determinasi sebesar 0,579 artinya Non Performing Financing dan Financing to Deposit Ratio secara simultan memiliki kontribusi pengaruh sebesar $57,9 \%$ terhadap Pembiayaan, sedangkan sisanya sebesar $42,1 \%$ dipengaruhi faktor lain.

\section{d. Uji Hipotesis}

Uji hipotesis Parsial (Uji t)

Pengujian hipotesis dengan uji $t$ digunakan untuk mengetahui hipotesis parsial mana yang diterima.

Tabel 9. Hasil Uji Hipotesis Non Performing Financing Terhadap Pembiayaan

\section{Coefficients ${ }^{\mathrm{a}}$}

Unstandardized Coefficients Standardized Coefficients

\begin{tabular}{l|r|r|r|r|r} 
Model & B & Std. Error & Beta & \multicolumn{1}{c}{ Sig. } \\
\hline 1 (Constant) & 34.835 & 6.121 & & 5.691 & .001 \\
\hline NPL (X1) & -1.013 & .347 & -.741 & -2.920 & .022 \\
\hline
\end{tabular}

a. Dependent Variable: Pembiayaan (Y)

Berdasarkan hasil pengujian pada tabel di atas, diperoleh nilai $\mathrm{t}$ hitung $<\mathrm{t}$ tabel atau $(-2,920<2,365)$, dengan demikian terdapat pengaruh 
yang negatif signifikan atara Non

Performing Financing terhadap

Pembiayaan.

Tabel 10. Hasil Uji Hipotesis Financing to Deposit Ratio Terhadap Pembiayaan Coefficients $^{\mathrm{a}}$

Unstandardized Coefficients Standardized Coefficients

\begin{tabular}{|c|c|c|c|c|c|}
\hline Model & B & Std. Error & Beta & $\mathrm{t}$ & Sig. \\
\hline 1 (Constant) & 42.326 & 9.154 & & 4.624 & .002 \\
\hline$F D R(X 2)$ & -.291 & .106 & -.722 & -2.759 & .028 \\
\hline
\end{tabular}

a. Dependent Variable: Pembiayaan (Y)

Berdasarkan hasil pengujian pada tabel di atas, diperoleh nilai $\mathrm{t}$ hitung $<$ t tabel atau $(-2,759>2,365)$, dengan demikian terdapat pengaruh yang negatif signifikan atara Financing to Deposit Ratio terhadap Pembiayaan.

Tabel 11. Hasil Uji Hipotesis Non Performing Financing dan Financing to Deposit Ratio Terhadap Pembiayaan

ANOVA $^{a}$

\begin{tabular}{|c|c|c|c|c|c|}
\hline Model & Sum of Squares & $\mathrm{df}$ & Mean Square & $\mathrm{F}$ & Sig. \\
\hline 1 Regression & 111.234 & 2 & 55.617 & 4.110 & $.075^{b}$ \\
\hline Residual & 81.199 & 6 & 13.533 & & \\
\hline Total & 192.433 & 8 & & & \\
\hline
\end{tabular}

Berdasarkan hasil pengujian pada tabel di atas, diperoleh nilai $\mathrm{F}$ hitung $<\mathrm{F}$ tabel atau $(4,110<4,760)$, dengan demikian terdapat pengaruh yang positif dan signifikan atara Non Performing Financing dan Financing to Deposit Ratio terhadap Pembiayaan.

\section{Pembahasan Hasil Penelitian}

\section{Pengaruh Non Performing Financing} Terhadap Pembiayaan

Non Performing Financing berpengaruh signifikan terhadap Pembiayaan dengan korelasi sebesar $-0,741$ atau memiliki hubungan yang negatif kuat dengan kontribusi pengaruh sebesar 54,9\%. Pengujian hipotesis diperoleh nilai $t$ hitung $<\mathrm{t}$ tabel atau $(-2,920<2,365)$. Dengan demikian terdapat pengaruh negtif signifikan antara Non Performing Financing terhadap Pembiayaan.

2. Pengaruh Financing to Deposit Ratio Terhadap Pembiayaan

Financing to Deposit Ratio berpengaruh signifikan terhadap Pembiayaan dengan korelasi sebesar $-0,722$ atau memiliki hubungan yang negatif kuat dengan kontribusi pengaruh sebesar 52,1\%. Pengujian hipotesis diperoleh nilai $t$

\section{Uji Hipotesis Simultan (Uji F)}

Pengujian hipotesis dengan uji $\mathrm{F}$ digunakan untuk mengetahui hipotesis simultan yang mana yang diterima. 
hipotesis diperoleh nilai $\mathrm{t}$ hitung $<\mathrm{t}$ tabel atau $(-2,920<2,365)$.

2. Financing to Deposit Ratio berpengaruh signifikan terhadap Pembiayaan dengan kontribusi pengaruh sebesar $52,1 \%$. Uji hipotesis diperoleh nilai $\mathrm{t}$ hitung $<\mathrm{t}$ tabel atau $(-2,759<2,365)$.

3. Non Performing Financing dan Financing to Deposit Ratio berpengaruh signifikan terhadap Pembiayaan dengan kontribusi pengaruh sebesar $57,9 \%$ sedangkan sisanya sebesar $42,1 \%$ dipengaruhi faktor lain. Uji hipotesis diperoleh nilai F hitung < $\mathrm{F}$ tabel atau $(4,110<4,760)$

\section{Saran}

1. Bank DKI Syariah dalam hal ini perlu lagi untuk menjaga tingkat rasio NPF nya agar tetap berada pada batas maksimal yang telah ditetapkan oleh BI. Bank DKI Syariah perlu menjaga kualitas pembiayaannya agar tidak terjadi permasalahan dalam penagihan kembali seperti kredit kurang lancar, diragukan bahkan macet.

2. Terkait dengan rasio Financing to Deposit Ratio (FDR), Bank DKI Syariah perlu menjaga agar nilai FDR tidak melebihi $110 \%$ seperti yang ditetapkan oleh BI, agar tingkat likuiditas bank DKI tetap berada pada level aman dan agar dapat memenuhi kebutuhan likuiditasnya.

3. Peningkatan Sumber Daya Manusia, dalam hal ini berkaitan dengan manajemen risiko dan analis pembiayaan. Perlu adanya peningkatan kompetensi agar pengelolaan manajemen risiko pada Bank DKI Syariah menjadi lebih baik, dan juga pembiayaan yang disalurkan Bank DKI Syariah akan lebih berkualitas dan tepat sasaran.

4. Bank DKI Syariah terus dapat memberikan dan meningkatkan pelayanan primanya kepada para nasabah dengan menghadirkan produk-produk perbankan yang lebih baik dan inovatif.

5. Untuk mendapatkan kepercayaan dari masyarakat, yaitu dengan meningkatkan faktor-faktor lain yang dapat meningkatkan pembiayaan dengan cara meningkatkan promosi melalui media cetak maupun elektronik, meningkatkan kualitas pelayanan baik dalam maupun diluar Bank DKI Syariah, meningkatkan fasilitas pelayanan untuk nasabah.

\section{DAFTAR PUSTAKA}

Agus Harjito \& Martono, (2010) "Manajemen Keuangan" Yogyakarta: Penerbit Ekonisia.

Agus Sartono. (2010). “Manajemen Keuangan Toeri dan Aplikasi”, Edisi keempat, Yogyakarta: Penerbit BPFE.

Algifari. (2015). "Analisis Regresi untuk Bisnis dan Ekonomi". Yogyakarta: BPFE.

Anjayani, NS., Lutfi, AM., Suhartono, A., Sari, WI., Sunarsi, D. (2020). Pengaruh Perputaran Persediaan dan Rasio Perputaran Aktiva Terhadap Return on Invesment Pada PT Gudang Garam Tbk. TIN: Terapan Informatika Nusantara. Vol. Issue 4 Pages 171-176

Antonio, Muhammad Syafi'I, "Bank Syariah Dari Teori Ke Praktek”, Gema Insani Press, Jakarta, 2011.

Arikunto, Suharsimi (2014). "Prosedur Penelitian Suatu Pendekatan Praktek". Jakarta: Rineka Cipta.

Ascarya, "Akad dan Produk Bank Syariah", Rajawali Pers, Jakarta, 2011.

Ayyub Muhammad, "Understanding Islamic Finance", Gramedia Pustaka Utama, Jakarta, 2009.

Bambang Riyanto, (2011). "Dasar-dasar Pembelanjaan Perusahaan". Edisi ke empat, BPFE Yogyakarta.

Fahmi, Irham (2012), "Pengantar Manajemen Keuangan" Cetakan pertama. Bandung: Penerbit Alfabeta.

Gianni, Nur Gilang, "Faktor yang Mempengaruhi Pembiayaan

Mudharabah Pada Bank Umum Syariah

Di Indonesia", Unnes: Jurnal Ekonomi, 2013.

Harahap, Sofyan Syafri, "Teori Akuntansi edisi Revisi 2011", Rajawali Pers, Jakarta, 2012.

Hasan Nurul Ichsan, M.A, "Perbankan Syariah (Sebuah Pengantar)”, Referensi (GP Press Grup), Jakarta, 2014.

Imam Ghozali (2017). "Aplikasi Analisis Multivariate Dengan Program SPSS". Edisi Kelima. Semarang: Badan Penerbit Undip. 
Istijanto (2014) "Riset Sumber Daya Manusia”. Jakarta: PT. Gramedia Pustaka

Jasmani, J. (2018). Pengaruh Kinerja Keuangan Terhadap Harga Saham (Analisis Pada Perusahaan Property dan Real Estate Yang Go Public di Bursa Efek Indonesia. Jurnal Akuntansi Indonesia, 12(2).

Jasmani, J. (2019). The Effect of Liquidity and Working Capital Turnover on Profitability at PT. Sumber Cipta Multiniaga, South Jakarta. PINISI Discretion Review, 3(1), 29-38.

K Nufus, H Supratikta, A Muchtar, D Sunarsi. (2020). Analysis of Financial Performance: Case Study of PT. X Employee Cooperative. Utopía Y Praxis Latinoamericana. Vol. 25. Pages 429444

Kasmir (2010), "Analisis Laporan keuangan", penerbit raja grafindo persada, Jakarta

Kasmir, (2010). "Pengantar Manajemen Keuangan”, Edisi Pertama, Cetakan kedua, Jakarta: Penerbit Prenada Media.

Kasmir. (2012) "Pengantar Manajemen Keuangan”, Edisi Pertama, Cetakan kedua, Jakarta: Prenada Media.

Martono dan Agus Harjito, (2011). "Manajemen Keuangan", Jakarta: Penerbit Ekonisia..

Munawir (2010), “Analisis Laporan Keuangan", Edisi Ke Empat, Penerbit Liberty, Yogyakarta.

Santoso, Singgih (2015). “Menguasai Statistik Multivariat". Jakarta: PT Elex Media Komputindo.
Sartono, "Manajemen Keuangan Aplikasi Dan Teori", Edisi Keempat, BPFE, Yogyakarta, 2008.

Sarwani, S., Akbar, I. R. ., Handoko, A. L. ., \& Ilham, D. . (2020). Pengaruh Pelatihan dan Motivasi terhadap Produktivitas Kerja Karyawan pada PT. Lion Mentari Airlines Bandara Internasional Soekarno Hatta Cengkareng. Jurnal Ilmu Komputer Dan Bisnis, 11(2a), 91100.

https://doi.org/10.47927/jikb.v11i2a. 24

Sawir, (2003). "Analisis Kinerja Keuangan dan Perencanaan Keuangan Perusahaan", Cetakan ketiga, Jakarta: Penerbit PT. Gramedia Pustaka Utama.

Sugiyarso, G. dan F. Winarni, "Manajemen Keuangan (Pemahaman Laporan Keuangan, Pengelolaan Aktiva, Kewajiban dan Modal serta Pengukuran

Sugiyono (2017), "Metode Penelitian Administrasi : dilengkapi dengan Metode R \& D". Bandung: Alfabeta.

Suhartono, A., Jati, W., \& Sunarsi, D. (2019). Pengaruh Earning Per Share Dan Return On Asset Terhadap Harga Saham Pada PT. Bank Negara Indonesia Tbk Periode 2009-2018. Jurnal Manajemen, Bisnis dan Organisasi (JUMBO), 3(3), 182-194.

Yonata, H. .., Setiawan, P., Santamoko, R. ., Ilham, D. ., \& Asdiany, D. . (2020). Pengaruh Kualitas Pelayanan dan Kepuasan Konsumen terhadap Loyalitas Pelanggan pada PT. Satria Antaran Prima. Jurnal Ilmu Komputer Dan Bisnis, 11(2), 2502-2514. https://doi.org/10.47927/jikb.v11i2.1 4 